\title{
Listeriosis in Association with Esch. coli Meningitis
}

\author{
P. CURTIS and P. A. LAMPORT ${ }^{\star}$ \\ From Hither Green Hospital, London S.E.13
}

A recent brief survey of listeriosis in man (Barber and Okubadejo, 1965) has indicated an increasing incidence of the disease in this country. No further cases have apparently been described since the above survey was published (N. S. Mair, 1966, personal communication). This described mainly meningeal infections, about half occurring in newborn infants as 'granulomatosis infantisepticum'.

Listeria monocytogenes appears to have a predilection for the meninges, except in pregnancy when the mother suffers a 'grippe' like illness, and the infant subsequently develops a generalized septicaemia usually following infection of the maternal genital tract (Rappaport, Rabinovitz, Toaff, and Krochik, 1960; Toaff, Krochik, and Rabinovitz, 1962). Alex (1955) investigated 6000 consecutive deliveries and noted that $2 \%$ of 358 neonatal deaths were caused by $L$. monocytogenes.

Listeria meningitis has also been noted to occur concurrently with both measles and pertussis in children (H. P. R. Seeliger, 1966, personal communication), but in general no obvious source of infection can be found in previously healthy children or adults suffering from this disease.

The case reported here is of a mixed meningitic infection caused by $L$. monocytogenes and Esch. coli, and underlines some of the problems in the aetiology, diagnosis, and treatment of this unusual disease.

\section{Case History}

A Nigerian boy aged 2 years was admitted to hospital in March 1966. He had been resident in England for one year. There was a six-day history of pyrexia, anorexia, and diarrhoea followed by signs of meningitis. On examination he was semiconscious with a temperature of $40^{\circ} \mathrm{C}$. $\left(104 \cdot 2^{\circ} \mathrm{F}\right.$.). There were marked meningitic signs and a convergent strabismus due to right lateral rectus palsy was noted.

Turbid yellow fluid was obtained on lumbar puncture containing 560 cells $/$ c.mm., $75 \%$ polymorphs, $25 \%$ endothelial cells. Film showed numerous small Gramnegative bacilli, and numerous diphtheroids were also

Received January 26, 1967.

^ Present address: Pathology Department, Whittington Hospital, Archway Road, London N.19. present. Blood culture: no growth. Blood picture: Hb 5.4 g. $/ 100 \mathrm{ml}$. WBC 5000 per c.mm., neutrophils 2050, lymphocytes 2450 , monocytes 450 . Hb genotype AA. Blood urea, $19 \mathrm{mg} . / 100 \mathrm{ml}$. Nose and throat swabs, no growth. Faeces, no pathogens. Chest $x$-ray film, normal.

Treatment was started with intramuscular chloramphenicol hemisuccinate $250 \mathrm{mg}$. six-hourly, and penicillin 250,000 units six-hourly. The following day the CSF culture was reported as showing Esch. coli, and treatment was continued with penicillin and chloramphenicol for five days followed by a further five days of chloramphenicol.

In view of the anaemia the patient received $400 \mathrm{ml}$. blood and a course of intramuscular 'jectofer' was given. His general condition improved slowly but he remained irritable and reluctant to feed. The strabismus persisted. The day after discontinuing chloramphenicol the temperature rose to $39^{\circ} \mathrm{C}$. $\left(102^{\circ} \mathrm{F}\right.$.) and the meningitic signs returned. A further lumbar puncture showed an increase in the CSF of both protein and cells. No organisms were seen. Therapy with intramuscular colomycin (known to penetrate the meninges in infants) was begun $(250,000$ units t.d.s.). The temperature giadually settled over the next six days and this treatment was continued for three weeks. Repeated lumbar punctures showed a reduction in cells and protein. However, three days after cessation of colomycin, $L$. monocytogenes was isolated from a spinal fluid sample. This suggested that a chronic listeria meningitis had been present since admission in addition to the Esch. coli infection. As the child's condition was satisfactory no further therapy was given until the organism was again grown from the CSF nine days later. Intrathecal penicillin 10,000 units daily for five days together with intramuscular penicillin 500,000 units six-hourly for 14 days was started. On this régime the CSF returned to normal, there were no neurological sequelae, and ocular movements were now full. He was discharged symptom free in June. At follow-up in August, lumbar puncture yielded normal CSF.

\section{Bacteriology and Serology}

CSF on admission produced a heavy growth of Esch. coli sensitive to chloramphenicol and colomycin. Five weeks later the CSF grew three colonies of a Grampositive bacillus $(0.5 \times 2 \cdot 0)$ on horse blood agar after 18 hours' incubation. The colonies showed typical characteristics of L. monocytogenes, with 'tumbling' 
motility in broth and peptone water cultures. The biochemical features were also consistent with $L$. monocytogenes, with the exception of overnight inulin fermentation which is not characteristic of most strains (H. P. R. Seeliger, 1966, personal communication).

Subcultures of Robertson's Cooked Meat medium containing $10 \%$ sodium chloride, incubated at $37^{\circ} \mathrm{C}$., continued to yield a heavy growth of the organisms after two months.

The organism was sensitive to discs containing chloramphenicol (10 $\mu \mathrm{g}$.), erythromycin (10 $\mu \mathrm{g}$.$) ,$ ampicillin $(2 \mu \mathrm{g}$.$) , cloxacillin (5 \mu \mathrm{g}$.$) , penicillin (1.5$ units), streptomycin $(10 \gamma \mathrm{g}$.$) , tetracycline (10 \mu \mathrm{g}$.). It was slightly sensitive to novobiocin ( $5 \mu \mathrm{g}$.) and resistant to colomycin $(50 \mu \mathrm{g}$.).

Animal inoculation. A monocytosis of $26 \%$ was obtained by intravenous inoculation of $0.5 \mathrm{ml}$. broth culture into a rabbit. Subsequent blood cultures yielded $L$. monocytogenes identical to that isolated from the patient. Attempts to isolate the organism from the faeces from both parents and the genital tract of the patient's mother were unsuccessful.

Cultures were sent to Professor Seeliger, Würtburg University, who typed the organism as $L$. monocytogenes type $4 b$.

Serology. Sera were collected from the parents and the patient 37 days after admission and examined for antibodies to $L$. monocytogenes by Professor Seeliger. No significant antibody levels were found. The results are set out in the Table.

TABLE

Antibodies to Listeria monocytogenes in Patient and Parents

\begin{tabular}{l|c|c}
\hline & Titres vs Patient's Organism & vs Type 4b \\
\cline { 1 - 2 } Mother & Negative & $1: 50$ \\
Father & Negative & $1: 100$ \\
Patient & $1: 50$ & $1: 100$ \\
\hline
\end{tabular}

\section{Discussion}

Mixed meningeal infection with L. monocytogenes has previously been described with tuberculous meningitis (Hoffmann and Boese, 1955; Luchmann and Hecker, 1957; Seeliger, 1961), but infection with other organisms has not been noted (H. P. R. Seeliger, 1966, personal communication). L. monocytogenes may be mistaken for other organisms such as $H$. influenzae (Insley and Hussain, 1964), corynebacterium, streptococci, erysipelothrix (Hoeprich, 1958), and pneumococcus (Seeliger, 1961).

In the case described above the organism was initially regarded as a diphtheroid and dismissed as a contaminant, a common mistake mentioned in a number of reports (Hoeprich, 1958; Ray and Wedgewood, 1964; Barber and Okubadejo, 1965). The presence of a purulent meningitis due to Esch. coli only added to this deception. Furthermore, there is no known specific picture in the CSF associated with listerial meningitis.

When the contaminating organism was eventually recognized as $L$. monocytogenes there was some difficulty in choosing a suitable antibiotic. In vitro sensitivity tests showed susceptibility to all drugs except colomycin. The Fig. shows the relative ineffectiveness of a short course of intramuscular penicillin and 10 days' therapy with chloramphenicol. There was, however, a gradual improvement in the CSF on colomycin. Listeria is often difficult to eradicate in spite of in vitro antibiotic sensitivity (Ray and Wedgewood, 1964), and it is our impression, after reviewing a number of reports, that the choice of an effective therapeutic agent frequently cannot be based on these tests. In view of the frequent lack of correlation between clinical response and in vitro antibiotic sensitivity, it is probably wise to institute high dosage therapy for a prolonged period, preferably with two antibiotics. Clinical cure is not an indication to stop therapy as the CSF may still be abnormal and a relapse will occur (Harding and Brunton, 1962).

It is interesting to speculate on the possible source of infection in this particular case. Possibly the listeria organism was acquired either transplacentally or by inoculation through the vagina (Barber and Okubadejo, 1965; Rappaport et al., 1960), and this suggestion is supported by the fact that the patient's mother had been unwell in the seventh month of her pregnancy. The illness consisted of abdominal pain, weakness, and pyrexia for five days. It is quite likely that listeria infections are common in Nigeria but as yet no convincing evidence for this has been put forward (O. A. Okubadejo, 1966, personal communication). It is, however, of interest that Professor Barber's patient (Barber and Okubadejo, 1965) also originated from West Africa.

Development of listeria infection in the first few months of life is probably due to perinatal infection (Gray, 1960; Dungal, 1961; Insley and Hussain, 1964), but there is no direct evidence to support the concept of congenital listeriosis exhibited later in childhood. However, it has been shown that the organism may be relatively non-pathogenic and remain in the CSF for long periods (Flamm, 1958). Lang (1955), using serological studies, showed that a significant number of mentally retarded children had raised antibody titres to listeria. This suggested prior occult listeria infection, but unfortunately 

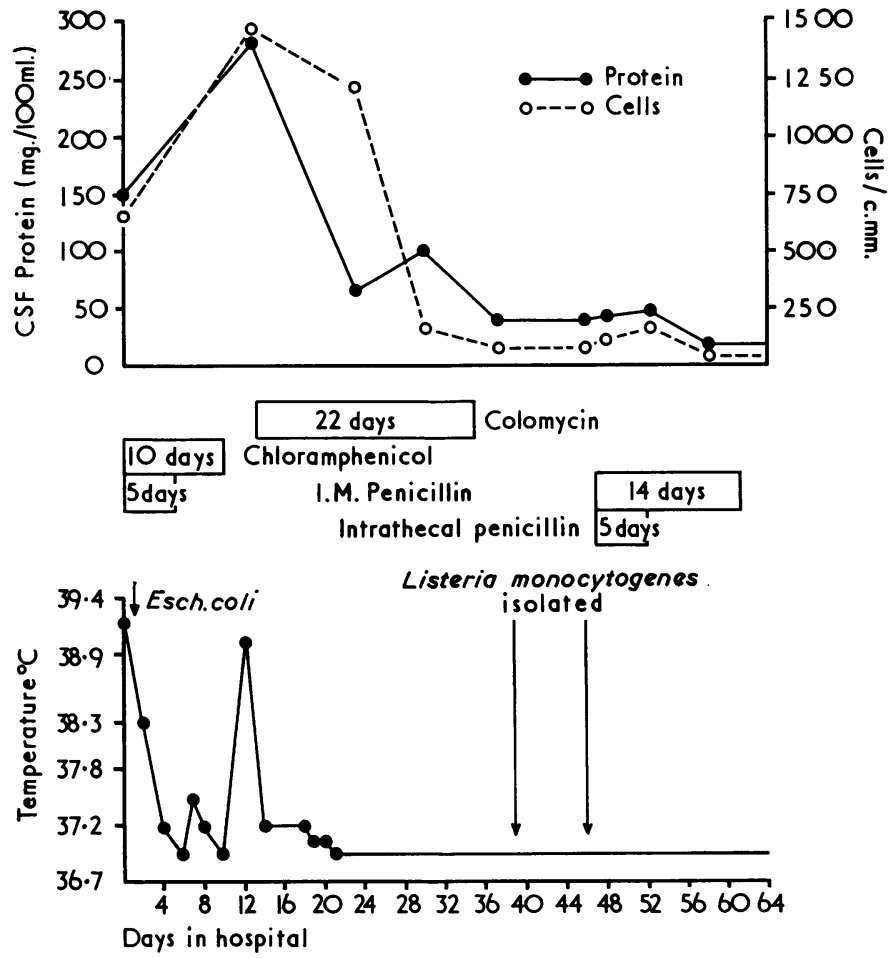

FIG.-Above: the relatively poor response in the CSF to antibiotic therapy. Below: normal temperatures at the time of Listerial infection.

antibody studies are often unreliable, as they were in this case.

It is difficult to believe that the mixed meningitis occurred spontaneously at the same time, and it could be suggested that a chronic listeria meningitis predisposed to subsequent infection with Esch. coli. The disease may certainly behave asymptomatically at birth (Ekelund, Laurell, Melander, Olding, and Vahlquist, 1962; Hood, 1961), and be followed by a very mild and prolonged illness.

In our patient such an illness would have to continue with relatively few symptoms for over $1 \frac{1}{2}$ years and such a situation would be most unlikely.

\section{Summary}

A case of mixed meningitis caused by Esch. coli and Listeria monocytogenes is described.

We would like to thank Dr. E. H. Brown for his advice and for allowing us to publish this case. We are indebted to Professor H. P. R. Seeliger of Würtburg University for his advice and sero-typing of the organism.

\section{REFERENCES}

Alex, R. (1955). Die approximative Häufigkeit der Listerioseinfektion in der Schwangerschaft. Arch. Gynäk., 186, 381.
Barber, M., and Okubadejo, O. A. (1965). Maternal and neonatal listeriosis. Brit. med. F., 2, 735.

Dungal, N. (1961). Listeriosis in four siblings. Lancet, 2, 513.

Ekelund, H., Laurell, G., Melander, S., Olding, L., and Vahlquist, B. (1962). Listeria infection in the foetus and the new-born. Acta paediat. (Uppsala), 51, 698.

Flamm, H. (1958). In Listeriosen Symposium, ed. E. Roots and D. Strauch. Zentr. Vet-Med., Suppl. 1, p. 61. Hamburg.

Gray, M. L. (1960). Genital listeriosis as a cause of repeated abortion. Lancet, 2, 315.

Harding, J. W., and Brunton, G. B. (1962). Listeria monocytogenes meningitis in neonates. Lancet, 2, 484.

Hoeprich, P. D. (1958). Infection due to Listeria monocytogenes. Medicine (Baltimore), 37, 143.

Hoffmann, H., and Boese, W. (1955). Zur Frage einer Vergesellschaftung von tuberkulose und Listeriose. Arztl. W/schr., 10, 417.

Hood, M. (1961). Listeriosis as an infection of pregnancy manifested in the newborn. Pediatrics, 27, 390.

Insley, J., and Hussain, Z. (1964). Listerial meningitis in infancy. Arch. Dis. Childh., 39, 278.

Lang, K. (1955). Zur Listeriose beim Kleinkind. Mschr. Kinderheilk., 103, 17.

Luchmann, A., and Hecker, P. (1957). Vier Fälle von Listeriose in einem Falle kombiniert mit einer meningitis tuberculosa. Dtsch. med. Wschr., 82, 1257.

Rappaport, F., Rabinovitz, M., Toaff, R., and Krochik, N. (1960). Genital listeriosis as a cause of repeated abortion. Lancet, 1 , 1273.

Ray, C. G., and Wedgewood, R. J. (1964). Neonatal listeriosis meningitis. Pediatrics, 34, 378.

Seeliger, H. P. R. (1961). Listeriosis. S. Karger, Basle.

Toaff, R., Krochik, N., and Rabinovitz, M. (1962). Genital listeriosis in the male. Lancet, $2,482$. 